\title{
An experimental study of translocation success and habitat improvement in wild rabbits
}

\author{
S. Cabezas \& S. Moreno \\ Department of Applied Biology, Estación Biológica de Doñana, Spanish Council for Scientific Research - CSIC, Sevilla, Spain
}

Keywords

European wild rabbit; habitat management; Mediterranean ecosystems; Oryctolagus

cuniculus; rabbit abundance; translocation.

\section{Correspondence}

Sonia Cabezas. Current address: Department of Biology, University of Saskatchewan, Sask. Canada S7N 5E2. Emails: scabezas@ebd.csic.es, sonia.cabezas@usask.ca

\begin{abstract}
The translocation of wild animals is a strategy frequently used in the conservation and management of natural populations. The aim of this study was to evaluate the impact of translocation (population supplementation) and habitat improvement on the abundance of European wild rabbit Oryctolagus cuniculus. We used eight open plots with different habitat treatments: two with increased shelter, two with increased food, two with increased shelter and food and two without habitat treatment (control plots). We translocated wild rabbits during 3 consecutive years, each year in four of the eight plots, with the remaining plots serving as control for the translocation treatment. Rabbit abundance (translocated plus native rabbits) was calculated by means of pellet counts, and the results were evaluated mainly by generalized linear mixed models. We found that rabbit abundance was determined primarily by habitat improvement. Rabbits were more abundant in treated than in control plots, and most abundant in the plots where food availability was increased. This effect persisted throughout the year. Translocation also increased abundance, but this effect was the strongest where shelter and food had also been improved and declined and disappeared after breeding. These findings suggest that the habitat is an important factor for rabbit abundance, with food availability being the prime factor regulating densities. Moreover, translocations on their own are only effective in the short term in situations in which factors limiting population growth (e.g. disease and predation) have not been corrected. Translocations should be carried out in conjunction with improvements in release habitat as rabbit densities will depend on the maximum carrying capacity of the habitat.
\end{abstract}

\section{Introduction}

Translocations of wild animals are one of the most-used strategies in conservation biology and in the management of natural populations (Griffith et al., 1989; Sarrazin \& Barbault, 1996; Wolf et al., 1996). Translocations are defined as the deliberate and mediated movement of wild individuals or populations from one area to another within their natural range (IUCN, 1996). Despite the frequency of these practices, several studies suggest that many translocations are not successful and fail to establish self-sustaining populations (Griffith et al., 1989; Wolf et al., 1996). Several factors have been associated with the success of translocations like the habitat quality, the number of animals released, the location of the release site in relation to the historical range of the translocated species and the status of the conservation of species, whether they are threatened, endangered or sensitive versus a native game species (Wolf et al., 1996; Fischer \& Lindenmayer, 2000). Although many variables that determine the success of a translocation have been taken into account when these practices are carried out, not all translocation programmes evaluate the factors associated with the success or are carefully monitored. Fischer
\& Lindenmayer (2000) concluded in their revision of translocation experiments that the main motivations of these movements of animals are, firstly, the solution of conflicts that arise between animal species and human social interests and, secondly, the strengthening of populations for hunting and conservation purposes.

European wild rabbit Oryctolagus cuniculus translocations fit well into this framework. The European wild rabbit is native to the Iberian Peninsula in south-western Europe (Rogers, Arthur \& Soriguer, 1994). Their range has expanded naturally to the Mediterranean area of southwestern continental Europe, and humans have introduced them worldwide for food or hunting (Monnerot et al., 1994). Whereas in most countries where rabbits are found they are considered a pest and it is necessary to control their populations (Drollette, 1996; Angulo, 2001), in Mediterranean ecosystems they are considered a key species. The importance of rabbits in the Iberian Peninsula is twofold: firstly, they are one of the peninsula's most important small-game species and thus generate important economic benefits (Angulo \& Villafuerte, 2003; Calvete, Angulo \& Estrada, 2005a) and secondly, they play an essential role in the conservation of the peninsula's biodiversity as a key element 
in the food chain of around 40 species of vertebrates (Delibes \& Hiraldo, 1981; Moreno, Villafuerte \& Delibes, 1996). Two principal rabbit predators are the Spanish imperial eagle Aquila adalberti and the Iberian lynx Lynx pardinus, both critically endangered species endemic to the Iberian Peninsula that are among the world's most threatened vertebrates (Nowell \& Jackson, 1996). In terms of diet, both species are considered rabbit specialists, and this lagomorph constitutes up to $80 \%$ of their total diets; thus, if rabbit populations decline, these two predators are directly affected and may become increasingly threatened with extinction (Ferrer \& Negro, 2004).

Over the last few decades, Iberian rabbit populations have declined sharply and in some areas the rabbit is now extinct (Villafuerte et al., 1995). This decline has been largely attributed to the fragmentation and loss of appropriate habitat (Moreno \& Villafuerte, 1995; Calvete et al., 2004) and the arrival of two viral infections: myxomatosis in the 1950s (Munoz-Goyanes, 1960) and rabbit hemorrhagic disease (RHD) at the end of 1988 (Arguello, Llanos \& Perez, 1988). Currently, both diseases are enzootic in the Iberian Peninsula and drastically raise mortality rates in wild rabbit populations every year (Calvete et al., 2002).

In order to palliate this marked decline in rabbit numbers, over the last few years, there has been a notable tendency toward the application of management techniques aimed at restoring or strengthening wild rabbit populations. Habitat management is the most frequently used strategy aimed at increasing the rabbit carrying capacity of a habitat. This type of management entails the elimination of scrub and the creation of more grazing pastures (Angulo, 2003). For example, in Donana National Park, one of the most important protected areas in Europe, habitat management aimed at increasing rabbit populations was the first strategy used in the first Iberian lynx and Spanish imperial eagle Recovery Plans, which ran between 1987 and 1996. Studies have suggested that the elimination of scrub in favour of pastures had positive results and that the number of wild rabbits increased (Moreno \& Villafuerte, 1995). The construction of artificial warrens to provide better shelter for breeding, functioning as a complement to vegetation treatment and translocations, is another method used to strengthen rabbit populations. However, to date, no studies have been carried out on the effectiveness of this strategy.

Another important management technique for wild rabbits is translocation. In Spain, Portugal and France, translocation is used to promote the recovery of natural populations and to improve hunting stocks (Letty et al., 2003; Calvete \& Estrada, 2004; Moreno et al., 2004). Rabbit translocations carried out in Spain can be classied as either re-introductions or population supplementations (IUCN, 1996; Angulo, 2003). With regard to conservation efforts, between 1993 and 2005, around 19000 rabbits were translocated to Donana National Park as part of the previously cited Recovery Plans (PND, 1993). Nevertheless, around only $4 \%$ of these rabbits have been part of scientific studies (Moreno et al., 2004; Calvete et al., 2005b; Cabezas, Calvete \& Moreno, 2006). Thus, despite the proliferation of translo- cation programmes, little research has ever been carried out into their effectiveness.

For the first time, this study evaluates the independent and combined effects of translocation (as a populationsupplementation strategy) and the improvement of habitat on the abundance of wild rabbits in the Donana area. Donana National Park is one of the few places where the Iberian lynx and Spanish imperial eagle still co-exist and where considerable human and economic resources are being invested into the restoration of wild rabbit numbers. We analyzed the effects of habitat treatments and translocations within the year, looking at the monthly variations in rabbit abundance. We also analyzed the effects between years looking at the abundance for the months of maximum and minimum rabbit abundance. This allowed us to test not only whether the effects were within the year, but also whether they were maintained across years or were only within the year and disappeared from 1 year to another.

\section{Methods}

\section{Study area}

The study was carried out in Donana National Park, in the province of Huelva, south-west Spain. The climate is typically Mediterranean, and the landscape is characterized by natural scrub vegetation and sparse native trees (GarciaMurillo \& Sousa, 1999).

\section{Treatments applied to habitat}

We defined eight open square plots (4 ha each) of similar habitat that were separated from each other by a distance of between 1 and $6 \mathrm{~km}$. Two plots were not treated in any way and were used as experimental habitat control. In the six other plots, we performed three of the habitat treatment types most frequently used in rabbit conservation programmes: increased shelter, increased food and both increased shelter and food. (1) Increased shelter: in order to evaluate the effect of increasing the availability of shelter and breeding sites, we built eight artificial warrens in two of the eight plots. Warrens were built in the middle of September 1999, before carrying out the translocation experiments (see Table 1). We used two kinds of artificial warrens, four of each type per plot: (type 1) prefabricated plastic, circular warrens specific to wild rabbits, $3 \mathrm{~m}$ in diameter, with internal galleries and six entrances (Majanos Mayoral, SL, Marbella, Spain); and (type 2) warrens $4 \times 5 \mathrm{~m}$ in size built out of tree trunks creating galleries buried $1 \mathrm{~m}$ under the soil surface with five entrances made of plastic tubes. Both types were covered by branches. (2) Increased food supply: in order to evaluate the effect of increasing the availability of food, every year in autumn in two of the eight plots we sowed an area of 1 ha with the herbaceous crops barley Hordeum vulgare and oats Avena sativa. (3) Increased shelter and food: in order to evaluate the combined effect of increased shelter and food availability, in two of the eight 
Table 1 Number of European wild rabbits Oryctolagus cuniculus released in each one of the eight habitat treatment plots: two plots with increased shelter; two plots with increased food; two plots with increased shelter and food; two plots of habitat control, during the three translocation experiments, each in two batches

\begin{tabular}{|c|c|c|c|c|c|c|c|c|}
\hline \multirow[b]{3}{*}{ Translocation experiments } & \multicolumn{8}{|c|}{ Habitat treatment plots } \\
\hline & \multicolumn{2}{|c|}{ Shelter } & \multicolumn{2}{|c|}{ Food } & \multicolumn{2}{|c|}{ Shelter+food } & \multicolumn{2}{|c|}{ Habitat control } \\
\hline & 1 & 2 & 1 & 2 & 1 & 2 & 1 & 2 \\
\hline \multicolumn{9}{|l|}{ First } \\
\hline Batch 1: November 1999 & 33 & 0 & 33 & 0 & 34 & 0 & 33 & 0 \\
\hline Batch 2: February 2000 & 32 & 0 & 33 & 0 & 33 & 0 & 34 & 0 \\
\hline \multicolumn{9}{|l|}{ Second } \\
\hline Batch 1: December 2000 & 0 & 32 & 0 & 33 & 0 & 33 & 0 & 32 \\
\hline Batch 2: February 2001 & 0 & 32 & 0 & 31 & 0 & 32 & 0 & 32 \\
\hline \multicolumn{9}{|l|}{ Third } \\
\hline Batch 1: January 2002 & 0 & 33 & 0 & 33 & 0 & 33 & 0 & 33 \\
\hline Batch 2: March 2002 & 0 & 33 & 0 & 33 & 0 & 33 & 0 & 33 \\
\hline
\end{tabular}

plots, we built eight artificial warrens (four of each type per plot) and sowed an area of 1 ha with herbaceous crops.

\section{Design of the translocation experiments}

Between 1999 and 2002, three translocation experiments with wild rabbits were carried out, each in two batches (see Table 1). Rabbits were brought from various sites in the provinces of Cadiz and Huelva (both SW Spain) and located to an area ranging from 44 to $250 \mathrm{~km}$ away from the genetically similar recipient population in the Donana National Park (Branco, 1995). After capture, rabbits were kept individually in cages in quarantine for a period of between 2 and 4 weeks. All rabbits were weighed, sexed and identified by a small numbered metal tag placed in the earflap. Subsequently, all rabbits were inoculated subcutaneously with commercial vaccines against both diseases at doses recommended for domestic rabbits (myxomatosis: Mixohipra FSA, Hipra Laboratory; RHD: ARVILAP, Ovejero Laboratory), and then subjected to internal and external deparasitization including subcutaneous inoculations against nematodes with levamisol (Nemisol, Ovejero Laboratory, Leon, Spain) and cestodes with praziquantel (Droncit, Bayer Hispania Lab., Barcelona, Spain), and the oral administration of triclabendazole against trematodes (Fasinex, Novartis Farmaceutica Laboratory, Barcelona, Spain).

The first translocation experiment (batch 1: November 1999 and batch 2: February 2000) was carried out in four of the eight experimental plots: in one of each of the treatments type (food, shelter, food and shelter) and in one control (see Table 1). Each of the four plots with translocation was thus labelled as a 'translocated' treatment, while the remaining four plots (one each of food, shelter, food and shelter and control) were considered as 'not translocated.' After the first translocation experiment, in order to determine whether the differences found in rabbit abundance between 'translocated' and 'not translocated' plots with the same habitat treatment were due to the translocation and not due to other characteristics of the plot, the second translocation experi- ment (batch 1: December 2000 and batch 2: February 2001) was carried out on 'not translocated' plots of the first translocation experiment. Thus, plots with the previous treatment of 'translocated' changed to 'not translocated' and 'not translocated' changed to 'translocated.' The third translocation experiment (batch 1: January 2002 and batch 2: March 2002) was carried out in same plots used for the second one. During each translocation experiment between 31 and 34 adult rabbits chosen at random were released per batch and per plot (see Table 1) with a sex ratio of c. 1:1. Rabbits were released directly into the chosen habitat (approximately in the center of the plot) in groups of three to four individuals distributed homogenously throughout the scrub. In the plots with artificial warrens, rabbits were released inside the warrens.

\section{Estimation of relative rabbit abundance}

The relative abundance of rabbits was estimated by the widely used method of pellet counts (Taylor \& Williams, 1956; Palomares, 2001). This method consisted of periodical counts performed every 2 months from September 1999 until November 2002. We counted rabbit pellets in 33 fixedposition sampling areas in each of the eight plots. Each sampling area was circular with a $0.5 \mathrm{~m}$ diameter, located c. $15 \mathrm{~m}$ apart, and distributed in two linear transects placed diagonally from one corner to the other of the square plot, crossing through the centre of the plot. During each count, all the pellets found were removed so that only the excrements deposited in the following 2 months would be taken into account during the subsequent count. At the beginning of September 1999, before carrying out the first sowing and the building of warrens but after having removed all the pellets from each sampling area in July 1999, the first pellet count was carried out in all the plots in order to estimate rabbit abundance before the translocation experiments began (see preliminary tests in 'Statistical analysis'). Given that the persistence of pellets in the field may vary according to the type of habitat and season of the year (Taylor \& Williams, 1956; Iborra \& Lumaret, 1997; Palomares, 2001), 
we calculated the daily persistence of the pellets for areas of scrub and crops independently (see Palomares, 2001). After the count, in 10 sampling areas in the scrub and in 10 areas in the crops, we placed 30 fresh pellets (having removed all the old pellets) marked with paint in order to calculate during the following count the number of pellets that were still there. Thus, we were able to calculate the daily persistence (DP) rates according to the following formula:

$$
\text { DP } 1 / 4 \partial F=I p^{1=n d}
$$

where $\mathrm{F}$ is the final number of marked pellets, I the initial number of marked pellets and nd the number of days between counts. The total number of pellets (n) was corrected with the daily persistence by the formula:

$$
\mathrm{N}^{1 / 4} \text { OðDP }-1 \mathrm{p}=ð \mathrm{DP}^{\mathrm{nd}}-\mathrm{DPp}
$$

where $\mathrm{O}$ is the number of pellets observed.

The abundance index used in the statistical analysis corresponded to the number of pellets (n) corrected by the above formulas and expressed in terms of surface area (pellets $\mathrm{m}^{-2}$ ).

\section{Statistical analysis}

Before carrying out the three translocation experiments, and in order to evaluate whether the chosen habitat treatment plots and the habitat controls showed differences in rabbit abundance, we carried out three preliminary tests, one for each habitat treatment with respect to the habitat control plots using generalized linear models. In the three tests, the dependent variable was the relative abundance index (pellets $\mathrm{m}^{-2}$ ) as determined in the pellet counts carried out in September 1999, which presented a g-type error distribution and a log-link function, and the plot as the independent variable.

The evaluation of the effect of translocation experiments and habitat treatments on rabbit abundance was carried out with generalized linear mixed models (Littell et al., 1996). The following models were performed:

Model 1 evaluated the monthly variation in rabbit abundance during the whole survey period. The dependent variable used was the rabbit abundance index (pellets $\mathrm{m}^{-2}$ ), which presented a g-type error distribution and a log-link function. Given that the first translocation was carried out in November 1999, the rabbit abundance data included in this model corresponded to the pellet counts carried out from January 2000 to November 2002. We included the following independent variables: month (six levels), habitat treatment (four levels), translocation treatment (two levels, 'translocated' vs. 'not translocated'), year (three levels) and the interaction between habitat treatment and translocation treatment. The release plot (eight levels) was included as a random variable in the model.

Models 2 and 3 evaluated the effect of habitat and translocation treatments on rabbit abundance during the months of maximum (Model 2) and minimum (Model 3) population numbers. The dependent variables were the rabbit abundance index (pellets $\mathrm{m}^{-2}$ ) corresponding to the
July months (Model 2) and November months (Model 3), both with a g-type error distribution and a log-link function. The independent variables for both models were habitat treatment (four levels), translocation treatment (two levels), year (three levels) and the interaction between habitat and translocation treatments. The release plot (eight levels) was included as a random variable in both models.

\section{Results}

The results from preliminary analysis showed that before the habitat treatments were applied, there were no significant differences in rabbit abundances between the plots selected for habitat treatment and the habitat control plots (increased shelter vs. habitat control: $\mathrm{w}_{3,114}^{2}=6.61$, $\mathrm{P}=0.085$; increased food vs. habitat control: $\mathrm{w}_{3,116}^{2}=4.19$, $\mathrm{P}=0.241$; increased shelter and food vs. habitat control: $\left.\mathrm{w}_{3,110}^{2}=1.92, \mathrm{P}=0.590\right)$.

Model 1 showed that during the whole study period, rabbit abundance varied markedly from 1 month to another (Fig. 1, Table 2): the maximum values were recorded in July, with an average ( $\mathrm{T} \mathrm{SE}$ ) of $19.50 \mathrm{~T} 2.49$ pellets $\mathrm{m}^{-2}$, and the minimum values in November, with an average ( $T \mathrm{SE}$ ) of $3.21 \mathrm{~T} 0.28$ pellets $\mathrm{m}^{-2}$. Also, there was significant interannual variation in abundance: an analysis of data from the whole study period and from just the months of July and November (Fig. 1, Table 2) showed that 2001 was the year with the greatest rabbit abundance. The results showed that during the study period, rabbit abundance depended on the treatment applied to the habitat (Table 2, Fig. 2). Post hoc comparisons between pairs of treatments showed that rabbit abundance was significantly lower in habitat control plots than in each of the habitat treatment plots, and that in increased food treatment plots, there was a greater abundance of rabbits than in increased shelter treatment plots

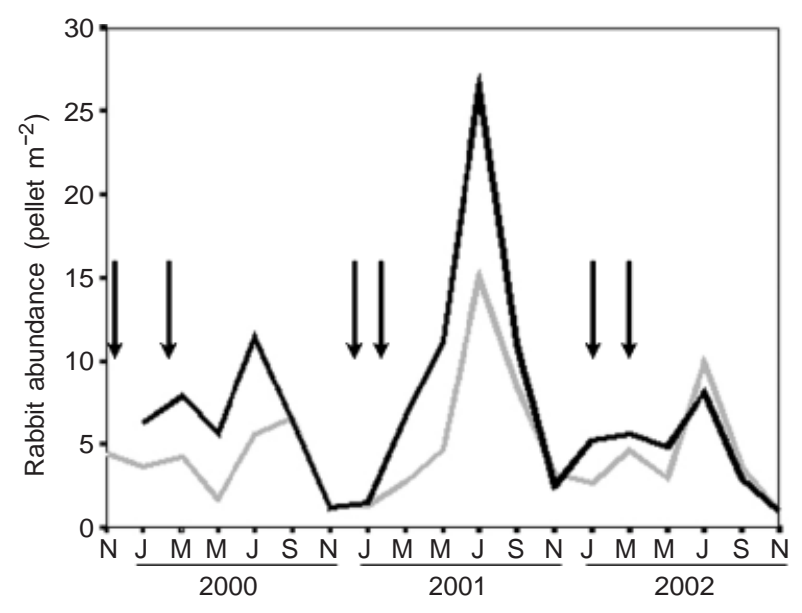

Figure 1 Averaged monthly variation of the rabbit abundance (pellets $\mathrm{m}^{-2}$ ) between November 1999 and November 2002. The black line represents the areas with translocations, and the grey line represents the zones without translocations. The arrows represent the periods in which the six wild rabbit translocations were carried out. 
Table 2 Results of the generalized linear mixed models performed on the monthly variation during the whole study period, and during the months of July and November

\begin{tabular}{|c|c|c|c|c|c|c|c|c|c|}
\hline & \multicolumn{2}{|c|}{ Whole study period } & \multirow[b]{2}{*}{$\mathrm{P}$} & \multirow{2}{*}{$\frac{\text { July }}{\mathrm{F}}$} & \multirow[b]{2}{*}{ d.f.n, d.f.d } & \multirow[b]{2}{*}{$\mathrm{P}$} & \multirow{2}{*}{$\begin{array}{l}\text { November } \\
\mathrm{F}\end{array}$} & \multirow[b]{2}{*}{ d.f.n, d.f.d } & \multirow[b]{2}{*}{$\mathrm{P}$} \\
\hline & $\mathrm{F}$ & d.f.n, d.f.d & & & & & & & \\
\hline Month & 93.06 & 5,4733 & 00.0001 & & & & & & \\
\hline $\mathrm{HA}$ & 7.31 & 3,4733 & O0.0001 & 1.38 & 3,778 & 0.2462 & 5.28 & 3,778 & 0.0013 \\
\hline TR & 48.63 & 1,4733 & 00.0001 & 10.06 & 1,778 & 0.0016 & 1.70 & 1,778 & 0.1932 \\
\hline $\mathrm{HA} \times \mathrm{TR}$ & 4.66 & 3,4733 & 0.0030 & 4.36 & 3,778 & 0.0047 & 2.93 & 3,778 & 0.0329 \\
\hline Year & 34.93 & 2,4733 & 00.0001 & 31.28 & 2,778 & O0.0001 & 33.29 & 2,778 & $\mathbf{0} 0.0001$ \\
\hline
\end{tabular}

$\mathrm{HA}$, habitat treatment variable; TR, translocation variable; HA $\times$ TR, the interaction between both; d.f.n, degrees of freedom of numerator; d.f.d, degrees of freedom of denomenator.
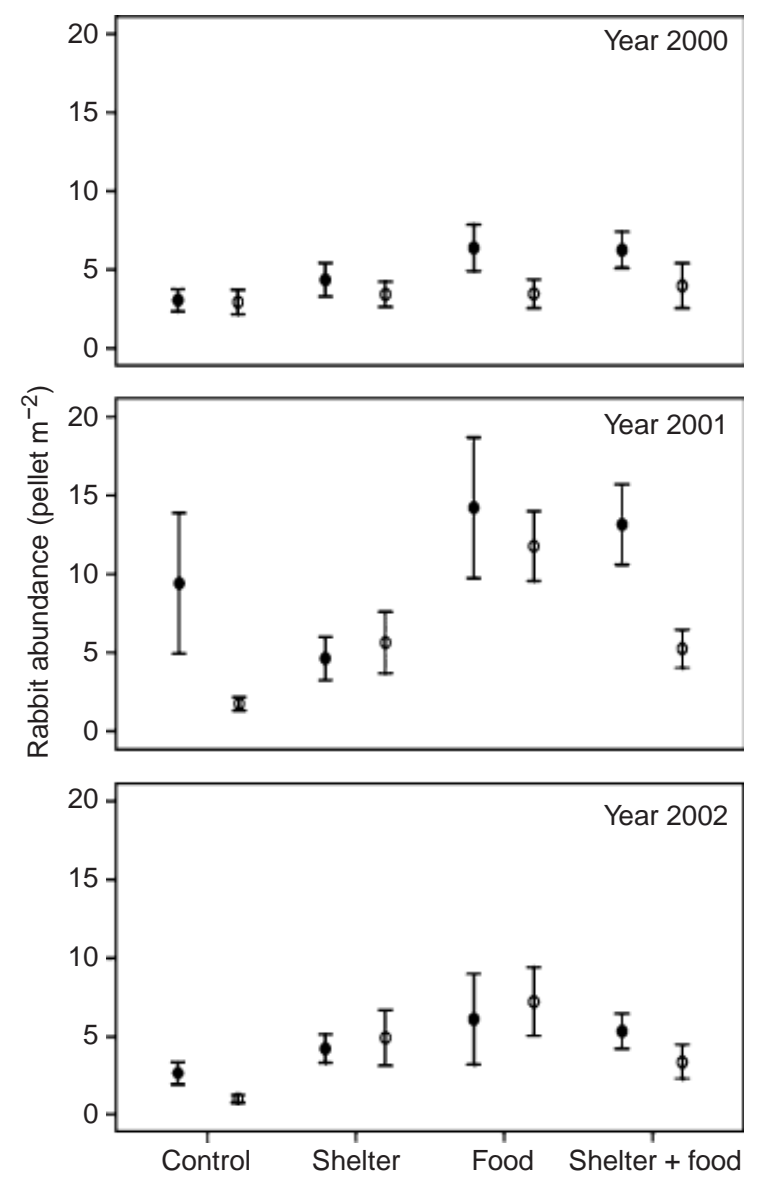

Figure 2 Rabbit abundance (pellets $\mathrm{m}^{-2}$ ) in each year of study (2000, 2001 and 2002) for the different treatments applied to the habitat. The solid symbols represent the plots with translocation and the empty symbols represent the plots without translocation. The error bars represent a $95 \%$ confidence interval.

(Table 3). Rabbit abundance was positively correlated to translocation treatment and the interaction between habitat treatment and translocation treatment was also significant (Table 2). In the latter case, the increase in abundance was greater when the translocation treatment was carried out in the increased shelter and food plots and in the habitat control plots (Table 3).
Model 2 showed that in the months of July (months with the maximum rabbit abundance), rabbit abundance was positively correlated to the translocation treatment (Table 2 ). The habitat treatment alone did not significantly affect rabbit abundance; rather, it was the interaction between the translocation treatment and the habitat treatment that was correlated to rabbit abundance (Table 2). Post hoc comparisons between 'translocated' and 'not translocated' pairs for each habitat treatment showed that abundance was significantly higher when the translocation treatment was carried out in the increased food and in the increased shelter and food treatment plots, as well as in the habitat control plots (Table 3, Fig. 3).

The results of the Model 3 showed that in the months of November (months with the lowest rabbit abundance), the rabbit abundance depended on the habitat treatment but not on translocation treatment (Table 2). Post hoc comparisons between pairs of habitat treatments showed that rabbit abundance was significantly greater in the habitat control plots (Table 3, Fig. 3). Although the translocation treatment did not increase rabbit abundance, the interaction between habitat and translocation treatments was correlated to rabbit abundance (Table 2). Post hoc comparisons between 'translocated' versus 'not translocated' pairs for each habitat treatment showed that this interaction was only caused by a lower rabbit abundance in the increased food treatment plot when the translocation treatment was carried out (Table 3).

\section{Discussion}

The density of natural populations of a species is positively correlated to habitat quality (Van Horne, 1983). In the case of the European wild rabbit, various studies have demonstrated that their abundance is determined by factors related to the characteristics of the habitat (Fa, Sharples \& Bell, 1999; Virgos et al., 2003; Calvete et al., 2004). In our study, rabbit abundance was determined by the treatment applied to the habitat and, in particular, increased food treatment was found to be the main factor influencing abundance. The increase of food availability had a positive effect on rabbit abundance during the whole study period, although in the months of maximum density (July), abundances increased in a similar manner in all the treatments and control plots. This 
Table 3 Average values ( $T \mathrm{sE}$ ) of rabbit Oryctolagus cuniculus abundance (pellets $\mathrm{m}^{-2}$ ) for the different habitat treatments (HA), and for the treatments depending on whether translocation took place or not (TR)

\begin{tabular}{|c|c|c|c|c|c|c|c|c|c|}
\hline \multirow[b]{2}{*}{ Post-hoc } & \multicolumn{3}{|c|}{ Whole study period } & \multicolumn{3}{|l|}{ July } & \multicolumn{3}{|c|}{ November } \\
\hline & Mean & $\mathrm{SE}$ & $\mathrm{PH}$ & Mean & $\mathrm{SE}$ & $\mathrm{PH}$ & Mean & $\mathrm{SE}$ & $\mathrm{PH}$ \\
\hline \multicolumn{10}{|l|}{ Between treatments } \\
\hline SF & 4.54 & 0.28 & a & 10.22 & 1.35 & $\mathrm{a}$ & 1.37 & 0.16 & $\mathrm{a}$ \\
\hline SF & 8.20 & 0.55 & $\mathrm{~b}$ & 19.49 & 2.49 & $\mathrm{a}$ & 2.73 & 0.32 & $\mathrm{a}$ \\
\hline $\mathrm{C}$ & 6.23 & 0.33 & $a, b$ & 12.56 & 1.08 & a & 1.87 & 0.24 & $\mathrm{a}$ \\
\hline $\begin{array}{l}\text { HA }(\mathrm{S}) \times \text { translocation } \\
\text { S without TR }\end{array}$ & 3.46 & 0.40 & c & 8.73 & 2.23 & $\mathrm{a}$ & 0.99 & 0.13 & $\mathrm{~b}$ \\
\hline S with TR & 4.67 & 0.47 & a & 12.71 & 2.38 & a & 1.44 & 0.24 & $\mathrm{a}$ \\
\hline $\begin{array}{l}\mathrm{HA}(\mathrm{F}) \times \text { translocation } \\
\mathrm{F} \text { without TR }\end{array}$ & 4.41 & 0.33 & a & 7.74 & 1.24 & a & 1.31 & 0.21 & $a$ \\
\hline F with TR & 7.49 & 0.56 & a & 15.76 & 2.44 & $\mathrm{~b}$ & 3.50 & 0.54 & $b$ \\
\hline $\begin{array}{l}\text { HA }(\text { SF }) \times \text { translocation } \\
\text { SF without TR }\end{array}$ & 8.92 & 0.94 & a & 23.23 & 4.34 & a & 1.96 & 0.34 & $a$ \\
\hline SF with TR & 4.21 & 0.37 & $b$ & 8.97 & 1.29 & b & 1.58 & 0.27 & $a$ \\
\hline $\begin{array}{l}\mathrm{HA}(\mathrm{C}) \times \text { translocation } \\
\mathrm{C} \text { without TR }\end{array}$ & 8.25 & 0.53 & a & 16.15 & 1.65 & $a$ & 2.17 & 0.41 & $a$ \\
\hline C with TR & 1.89 & 0.16 & b & 3.92 & 0.67 & b & 1.15 & 0.20 & $\mathrm{a}$ \\
\hline
\end{tabular}

with respect to type of treatment. Values correspond to the analysis carried out on a monthly basis, during the whole study period, and during the months of July and November. The codes for the habitat treatments are as follows: S, increased shelter; F, increased food; SF, increased shelter and food; C, habitat control.

Variables that share the same letter are not significantly different.

increase in rabbit abundance in plots with increased food availability reflects the attraction of trophic resources for both resident rabbits from neighbouring areas and translocated rabbits in the case of translocation treatment plots. Similar results were found by Moreno \& Villafuerte (1995) in an area near our study plots, in which rabbit abundance was seen to increase up to fourfold when food availability was increased by habitat management. Nevertheless, during the period of lowest density (November), the positive effect of increased food availability on abundance persisted. These results are in agreement with the importance of trophic resources as regulatory mechanisms in rabbit populations, a role that is heightened in Mediterranean environments characterized by marked oscillations in annual primary production (Newsome, Parer \& Catling, 1989; Moreno \& Villafuerte, 1995).

Translocation had an especially positive effect on rabbit abundance during the post-breeding period (July). However, in November, the month with the minimum population levels, translocations conferred no benefits at all on rabbit abundance. This type of numerical response after an artificial increase in numbers has been found in other studies of wild rabbits (Moreno et al., 2004) and suggests that population increases resulting from translocations are magnified during the breeding season, but are essentially only temporary. Furthermore, we found that even carrying out translocations in two consecutive years in the same plots (2001 and 2002) led to no great population increase. This could simply be due to an effect of the intensity of the translocation (i.e. the number of rabbits translocated every year), which was affected by the mortality of translocated rabbits during the first days after release; this mortality is one of the factors that negatively affects the success of rabbit translocations (Letty et al. 2003; Calvete \& Estrada, 2004; Cabezas, 2005). This effect was compounded by the socalled 'predator-pit' phenomenon (Newsome et al., 1989), that is, when an external factor causes a significant and sudden decrease in population numbers in a system and depredation becomes the limiting factor that prevents the recovery of populations to previous levels. The rabbit populations in Donana that are at low levels may have been subject to this phenomenon ever since the arrival of RHD. Thus, translocations must try to increase population densities sufficiently to overcome this effect.

The success of translocations in increasing rabbit abundance depended on the type of habitat in which they were carried out. During the whole of the study period, rabbit abundance increased when translocations were carried out in increased food and shelter treatment plots, with the increases being especially apparent during July (when the highest populations were recorded). Also in July, the translocation treatment significantly increased rabbit abundance in the increased food treatment plots. However, in spite of the importance of food availability, for a prey species like the rabbit, population densities will always be closely related to the amount of shelter available in the habitat (Moreno et al., 1996; Villafuerte \& Moreno, 1997; Lombardi et al., 2003). This factor may be a determinant in the case of 


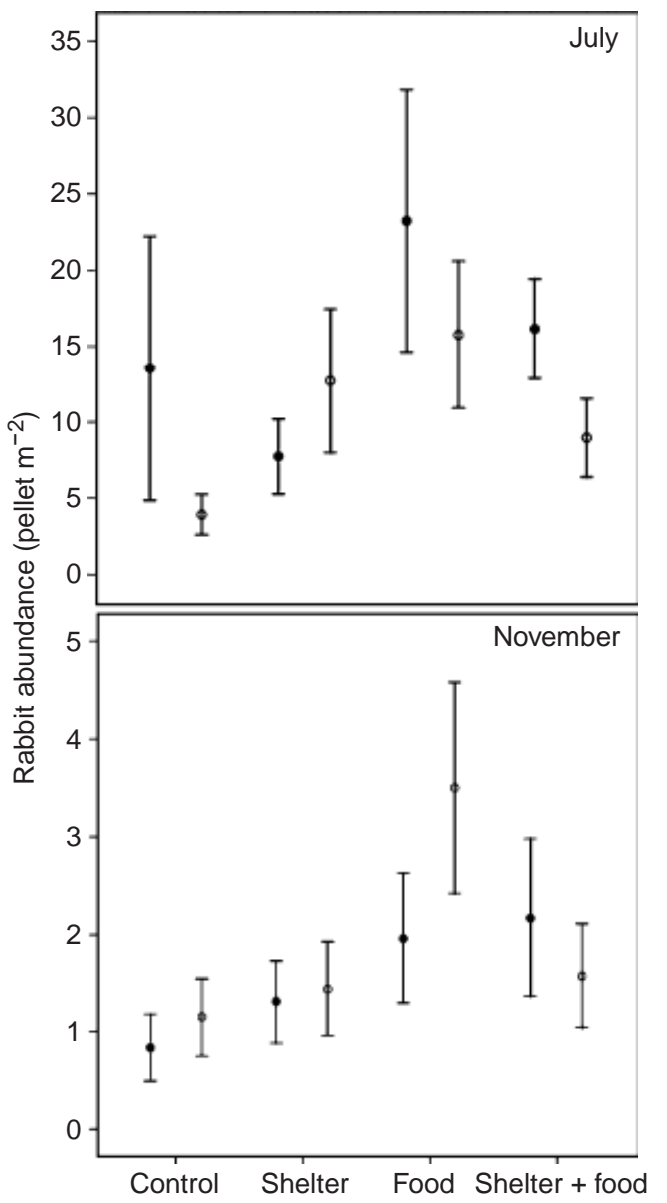

Figure 3 Rabbit abundance (pellets $\mathrm{m}^{-2}$ ) in the months of July (upper portion of the graphic), and in the months of November (lower portion of the graphic) for the different treatments applied to the habitat. The solid symbols represent the plots with translocation and the empty symbols represent the plots without translocation. The error bars represent a 95\% confidence interval.

rabbits translocated to a new, unknown habitat where predator pressure is especially high (Villafuerte, 1994). For this reason, the greatest increase in rabbit abundance was observed in plots with translocation treatment in the increased food and shelter treatment. This may be attributed to the fact translocated rabbits preferred increased food and shelter treatment plots and so used them more frequently (Cabezas, 2005) and/or because in these plots there was a greater chance to improve reproductive rates. Unfortunately, our data do not allow us to either confirm or reject these hypotheses.

During the post-breeding period, when young rabbits presumably increase population numbers, individual rabbits chose areas with greater food supply, possibly because in this period of the year the summer drought begins to affect trophic resources negatively. As a result, plots with increased food and increased food and shelter treatments provide more resources for feeding. Our results agree with those of Wolf et al. (1996), who showed that habitat quality is the determining factor in the success of translocations of wild animals.

Nevertheless, when translocations were carried out in the increased food treatment, a decline in rabbit abundance was noted during the months of minimum population levels (November). This decline could have been caused by a number of factors. On the one hand, this decline in abundance might be related to the carrying capacity of the environment. Given that the plots with increased food treatment registered the greatest levels of rabbit abundance during the whole study period (as well as during the breeding season), it is probable that the trophic resources in this habitat (sown crops) were exhausted more quickly after the breeding season than in the increased food treatment without translocation and that in November the resources were not sufficient to attract rabbits to this habitat. On the other hand, the explanation for the decline could be related to the statistical analysis. Given that the abundances in November were very low and that confidence intervals were very small, the smallest of changes due to factors not taken into account by this study could have ensured that the interaction between translocation and the increased food treatment was statistically significant.

The translocation treatment had a positive effect on rabbit abundance in habitat control plots. This increase in rabbit abundance due to the translocation treatment was possibly benefited from the fact that the survival rate recorded during the first days after release by rabbits translocated was greater in habitat control than in the rest of the habitat treatment plots (Cabezas, 2005). This fact, together with the low rabbit abundance found in habitat control plots without translocation treatment, could explain the significant differences in rabbit abundance among plots.

Monthly variations in rabbit abundance in our study closely mirrored the patterns described previously for the species in similar habitats (Beltran, 1991), with the maximum numbers observed after breeding and the minimum numbers in autumn. This variation is mainly due to the simultaneous effects of the high rate of reproduction of rabbits, which leads to rapid increases in population density, and their high mortality rates, above all among young rabbits, which reduce populations drastically to levels close to annual minimum levels once the breeding season is over (Wheeler \& King, 1985; Gibb, 1993; Villafuerte, 1994). Aside from seasonal changes, our results also showed that rabbit abundance varied during the 3 years of the study. In Mediterranean ecosystems, inter-annual variations in rabbit densities are mainly determined by annual precipitation and the length of dry periods (Palomares et al., 2001; Calvete et al., 2004). Although we did not evaluate the relationship between monthly precipitation and rabbit abundance, the great difference we found in the abundance levels between years was possibly related to fluctuations in rainfall during the study period. The greatest rainfall occurred in 2001, with an average of $709.2 \mathrm{~mm}$, while in 2000 and 2002, the average rainfall was only 496.7 and $560.6 \mathrm{~mm}$, respectively (data from the EBD Natural Processes Monitoring Team, CSIC). 
In conclusion, the results from our study showed the importance of habitat for rabbit abundance, with food availability being the prime factor regulating densities, even in the period in which the population levels were very low. This reinforces the importance of habitat management in any attempt at improving wild rabbit populations (Angulo et al., 2004; Calvete et al., 2004). Our results also showed that translocations increased rabbit abundance, principally during the breeding and post-breeding seasons. Nevertheless, the success of translocations was essentially dependent on the habitat quality of the release area and the highest abundance values were reached when translocations were carried out in habitats with greater food and shelter availability. During periods of low density, when rabbit abundance declines sharply, translocations had no effect on abundance. This result suggests that (1) translocations on their own are only effective in the short term in situations in which habitat factors limiting population growth (e.g. disease and predation) have not been corrected; (2) translocations should be carried out in conjunction with improvements in release habitat as rabbit densities will depend on the maximum carrying capacity of the habitat. If populations at low densities are subject to the predator-pit phenomenon, a possible solution would be to combine the two strategies, that is, combine translocations and habitat improvement, so that translocations enable rabbit densities to reach a point beyond which the predator-pit trap no longer applies and viable minimum populations are guaranteed.

\section{Acknowledgements}

We thank A. Melero, L. Lombardi, P. Rubio, R. Moreno and D. Doblas for their help during data collection, and Drs J. Blas, E. Angulo, C. Calvete and L. Bortolotti for their useful comments and for revising previous drafts of the manuscript. We thank M. Delibes for his comments and support. Dr Cowlishaw and two anonymous referees provided useful comments on previous manuscript drafts. The staff of Donana Natural Park provided technical and logistical support. The research was supported by FEDER (1FD1997-0789) and MCYT (BOS2001-2391-C02-01) projects.

\section{References}

Angulo, E. (2001). When DNA research menaces diversity. Nature 410, 739.

Angulo, E. (2003). Factores que afectan a la distribución y abundancia del conejo en Andalucía. PhD thesis, Complutense University, Madrid. Spain.

Angulo, E., Calvete, C., Cabezas, S. \& Villafuerte, R. (2004). Scrub management and rabbit translocations at Donana National Park: long and short-term effectiveness. Second World Lagomorph Conference. Vairao, Portugal.
Angulo, E. \& Villafuerte, R. (2003). Modelling hunting strategies for the conservation of wild rabbit populations. Biol. Conserv. 115, 291-301.

Arguello, J.L., Llanos, A. \& Perez, L.I. (1988). Enfermedad Hemorragica del conejo en Espana. Medicina Veterinaria 5, 645-650.

Beltran, J.F. (1991). Temporal abundance pattern of the wild rabbit in Donana, SW Spain. Mammalia 55, 591-599.

Branco, M.S. (1995). Contribuiçao para o estudo da genética bioquímica e populacional do coelho, Oryctolagus cuniculus. $\mathrm{PhD}$ thesis, University of Porto, Portugal.

Cabezas, S. (2005). Aplicaciones a la conservación del conejo silvestre: translocaciones y mejora del hábitat. PhD thesis, University of Sevilla, Spain.

Cabezas, S., Calvete, C. \& Moreno, S. (2006). Vaccination success and body condition in the European wild rabbit. J. Wildl. Mgmt. 70, 1125-1131.

Calvete, C., Angulo, E. \& Estrada, R. (2005a). Conservation of European wild rabbit populations when hunting is age and sex selective. Biol. Conserv. 121, 623-634.

Calvete, C., Angulo, E., Estrada, R. \& Cabezas-Ruiz, S. (2004). Habitat factors related to wild rabbit conservation in an agricultural landscape. Land. Ecol. 19, 531-542.

Calvete, C., Angulo, E., Estrada, R., Moreno, S. \& Villafuerte, R. (2005b). Quarantine length, blood biochemical parameters and survival of translocated European wild rabbits. J. Wildl. Mgmt. 69, 1063-1072.

Calvete, C. \& Estrada, R. (2004). Short-term survival and dispersal of translocated European wild rabbits. Improving the release protocol. Biol. Conserv. 120, 507-516.

Calvete, C., Estrada, R., Villafuerte, R., Osacar, J.J. \& Lucientes, J. (2002). Epidemiology of viral haemorrhagic disease and myxomatosis in free-living population of wild rabbits. Vet. Rec. 150, 776-782.

Delibes, M. \& Hiraldo, F. (1981). The rabbit as prey in the Iberian mediterranean ecosystems. In Proceedings of the World Lagomorph Conference: 614-622. Myers, K. \& MacInnes, C.D. (Eds). Ontario, Canada: University of Guelph and Wildlife Research, Ministry of Natural Resources.

Drollette, D. (1996). Australia fends off critic of plan to eradicate rabbits. Science 272, 191-192.

Fa, J.E., Sharples, C.M. \& Bell, D.J. (1999). Habitat correlates of European rabbit (Oryctolagus cuniculus) distribution after the spread of RVHD in Cadiz Province, Spain. J. Zool. (Lond.) 249, 83-96.

Ferrer, M. \& Negro, J.J. (2004). The near-extinction of two large European predators: the super-specialists pay a price. Conserv. Biol. 18, 344-349.

Fischer, J. \& Lindenmayer, D.B. (2000). An assessment of the published results of animal relocations. Biol. Conserv. 96, $1-11$.

Garcıa-Murillo, P. \& Sousa, A. (1999). Unidades de vegetacion del Parque Natural de Donana (sector Abalario). Lagascalia 21, 111-132. 
Gibb, J.A. (1993). Sociality, time and space in a sparse population of rabbits (Oryctolagus cuniculus). J. Zool. (Lond.) 229, 581-607.

Griffith, B., Scott, M., Carpenter, J. \& Reed, C. (1989). Translocation as a species conservation tool: status and strategy. Science 245, 477-480.

Iborra, O. \& Lumaret, J.P. (1997). Validity limits of the pellet group counts in wild rabbit (Oryctolagus cuniculus). Mammalia 61, 205-218.

IUCN (1996). IUCN/SSC guidelines for re-introductions. 41st Meeting of the IUCN Council, Gland, Switzerland.

Letty, J., Aubineau, J., Marchandeau, S. \& Clobert, J. (2003). Effect of translocation on survival in wild rabbit (Oryctolagus cuniculus). Mammal Biol. 68, 250-255.

Littell, R.C., Milliken, G.A., Stroup, W.W. \& Wolfinger, R.D. (1996). SAS system for mixed models. Cary, North Carolina, USA: SAS Institute.

Lombardi, L., Fernandez, N., Moreno, S. \& Villafuerte, R. (2003). Habitat-related differences in rabbit (Oryctolagus cuniculus) abundance, distribution, and activity. J. Mammal. 84, 26-36.

Monnerot, M., Vigne, J.D., Biju-Duval, C., Casane, D., Callou, C., Hardy, C., Mougel, F., Soriguer, R.C., Dennebouy, N. \& Mounolou, J.C. (1994). Rabbit and man: genetic and historic approach. Genet. Sel. Evol. 26, 167-182.

Moreno, S. \& Villafuerte, R. (1995). Traditional management of scrubland for the conservation of rabbits Oryctolagus cuniculus and their predators in Donana National Park, Spain. Biol. Conserv. 73, 81-85.

Moreno, S., Villafuerte, R., Cabezas, S. \& Lombardi, L. (2004). Wild rabbit restocking for predator conservation in Spain. Biol. Conserv. 118, 183-193.

Moreno, S., Villafuerte, R. \& Delibes, M. (1996). Cover is safe during the day but dangerous at night: the use of vegetation by European wild rabbits. Can. J. Zool. 74, 1656-1660.

Munoz-Goyanes, G. (1960). Anverso y reverso de la mixomatosis. Direccion General de Montes, Caza y Pesca Fluvial. Madrid.

Newsome, A.E., Parer, I. \& Catling, P.C. (1989). Prolonged prey suppression by carnivores predator-removal experiments. Oecologia 78, 458-467.

Nowell, K. \& Jackson, P. (1996). Wild cats: status survey and conservation action plan. Gland, Switzerland: International Union for Conservation of Nature Publications.
Palomares, F. (2001). Comparison of 3 methods to estimate rabbit abundance in a Mediterranean environment. Wildl. Soc. Bull. 29, 578-585.

Palomares, F., Delibes, M., Revilla, E., Calzada, J. \& Fedriani, J.M. (2001). Spatial ecology of Iberian Lynx and abundance of European Rabbits in southwestern Spain. Wildl. Monogr. 148, 1-36.

PND (1993). Memoria de actuaciones del Parque Nacional de Donana, ano 1993. Parque Nacional de Doñana, ICONA, Donana, Spain.

Rogers, P.M., Arthur, C.P. \& Soriguer, R.C. (1994). The rabbit in continental Europe. In The European rabbit. The history and biology of a successful colonizer: 22-63. Thompson, H.V. \& King, C.M. (Eds), New York: Oxford University Press.

Sarrazin, F. \& Barbault, R. (1996). Reintroduction: challenges and lessons for a basic ecology. TREE 11, 474-478.

Taylor, R.H. \& Williams, R.M. (1956). The use of pellet counts for estimating the density of populations of the wild rabbit, Oryctolagus cuniculus (I). New Zealand. J. Sci. Technol. 38, 236-256.

Van Horne, B. (1983). Density as a misleading indicator of habitat quality. J. Wildl. Mgmt. 47, 893-901.

Villafuerte, R. (1994). Riesgo de depredación y estrategias defensivas del conejo, Oryctolagus cuniculus, en el Parque Nacional de Donana, PhD thesis, University of Cordoba, Spain.

Villafuerte, R., Calvete, C., Blanco, J.C. \& Lucientes, J. (1995). Incidence of viral hemorrhagic disease in wild rabbit populations in Spain. Mammalia 59, 651-659.

Villafuerte, R. \& Moreno, S. (1997). Predation risk, cover type, and group size in European rabbits in Donana (SW Spain). Acta Theriol. 42, 225-230.

Virgos, E., Cabezas-Diaz, S., Malo, A., Lozano, J. \& LopezHuertas, D. (2003). Factors shaping European rabbit (Oryctolagus cuniculus) abundance in continuous and fragmented populations of central Spain. Acta Theriol. 48, 113-122.

Wheeler, S.H. \& King, D.R. (1985). The European rabbit in south-western Australia. II.-Reproduction. Aust. Wildl. Res. 12, 197-212.

Wolf, M.C., Griffith, B., Reed, C. \& Temple, S.A. (1996). Avian and mammalian translocations: update and reanalysis of 1987 survey data. Conserv. Biol. 10, 1142-1154. 